FROM THE CHMLREX'S KLINIK OF KAROIINSKA INSTITUTET IX ALL-

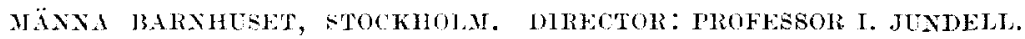

\title{
On mixed diet during the first year of life.
}

\section{JUNDELL.}

\section{First paper. ${ }^{1}$}

The general opinion with regard to the age, which an infant ought to have reached, before a mixed diet can be administered, is that an ordinary mixed diet ought not to be given, before the child is twelve months old. As representatives of this opinion I may quote CzerNy and KeLtere, who in their well-known text-book "Des Kindes Ernährung etc." say that eggs, meat and vegetables ought not to be given till the child has entered its second year. Shortly after I had begun my own trials with mixed diet during the first year, Stolte, however, published (Jahrb. f. Kinderheilkunde 1914, Bd 30) a paper from CzenNy's own Clinic, with an account of some cases, where a mixed diet had been given during the last quarter of the first year of life. SToute seems chiefly to have been guided by the idea, that infants $n$ clinics lead too monotonous an existence, especially

${ }^{1}$ I gave a report of this first part of my investigations regarding mixed diet during the first year of life at the First Northern Congress of Pediatries in Copenhagen, Angust 14-16, 1919. As these observations have not been printed in any other language than Swedish, and as they form the introduction to continued experiments in the same question, which are to be published in this journal, I have considered it desirable to publish this first paper in the present way. 
from a psychical point of view. He expects to be able to arrive at a better result in the treatment of infants in hospitals by letting them have more variety in the psychical treatment, especially also with regard to the quantity and the nature of their food. In this, SToute does not seem to have had any special intention of experimenting with a mixed diet, and it only seems to have been actually administered in a fairly small number of cases.

My own investigations I began before Storte had published his paper, and I simply started from the idea, that nothing proves the necessity of feeding the child almost exclusively with milk food for such a long time as has hitherto been usual. In other words, I asked myself whether the mixed food of the adult might not, with certain restrictions, be used with advantage much earlier than is now done.

Table I.

Total number of infants (children under one year) tended in the Orphan Asylum during the years 1914-1918.

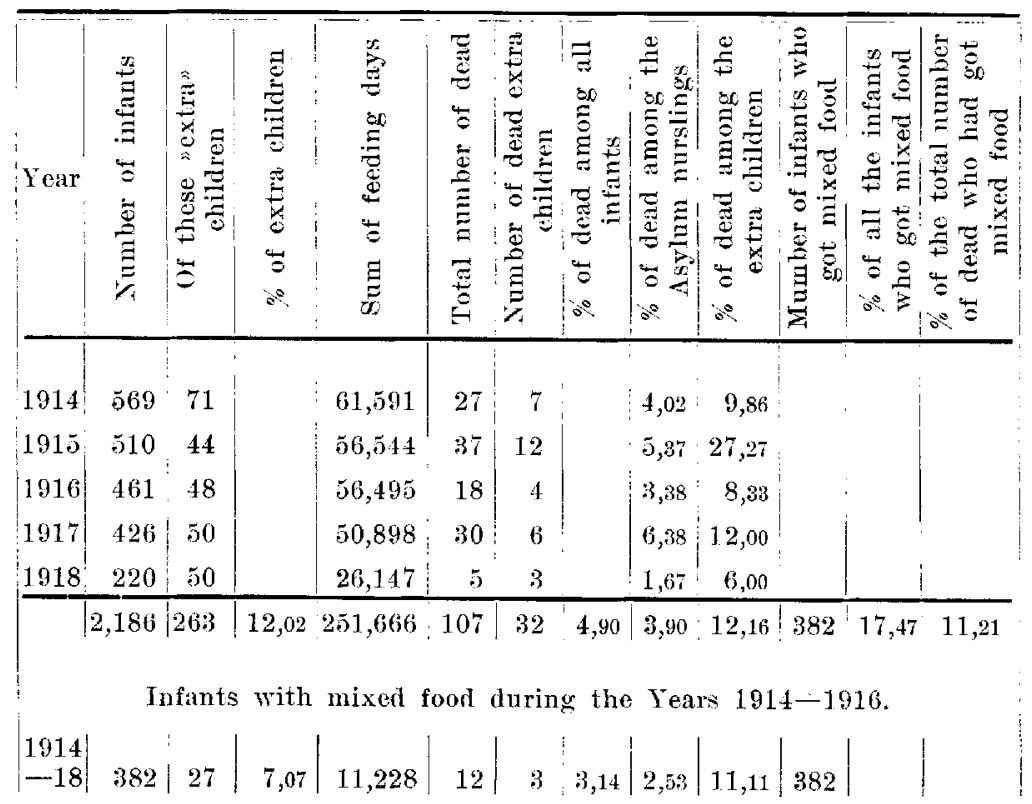


It is true that in later years the strictly pure milk diet, which was the ordinary one up till some ten years ago, has been abandoned. The majority of modern specialists in diseases of children have carried it so far, that they often prescribe beef-tea, certain kinds of groats, fruit syrups and some light regetables as soon as the child is six months old. These dishes, however, have in the main been mostly of the nature of appetising morsels, which does not prevent them from having a decided importance with regard to feeding in certain respects. But, as $I$ have mentioned, a diet that may be said to be really equalvalent to the mixed food of the adult, has not yet been tried during the first year of life.

Since 1914, I have been making extensive experiments in the Orphan Asylum (Allmänna Barnhuset) of Stockholm with mixed diet for children during the second half of their first year. Table I gives a summary of my trials. It is seen from this table, that the total number of children less than a year old, who have been tended in the Asylum during the years $1914-1918$, is 2,186 , of which 263 are so-called extra children, $i$. e. children, who are admitted only for nursing during a shorter period, whereas the others are nursed for a longer time. Out of these 2,186 children less than a year old 382 in all have been given a mixed diet. I have not yet had time to examine the result of the feeding in all these 382 cases; up till now only 68 cases have been examined in detail. I have selected these 68 cases in the following manner: first of all $I$ have taken all the infants who received mixed food during the years 1914-1915. Among the infants getting mixed diet during the years 1916-1918 I have only chosen those, who were first given mixed diet during the periods January 1st-February 16th and July 15th-August 31 st in each of the last mentioned 3 years. I have let the choice be governed by fixed periods of the year; this was done lest the choice should be fortuitous. Further, in fixing the periods I have chosen one period of the year, when the state of health in the Orphan Asylum is generally at ist lowest, and another, equally long, period, when generally, the 


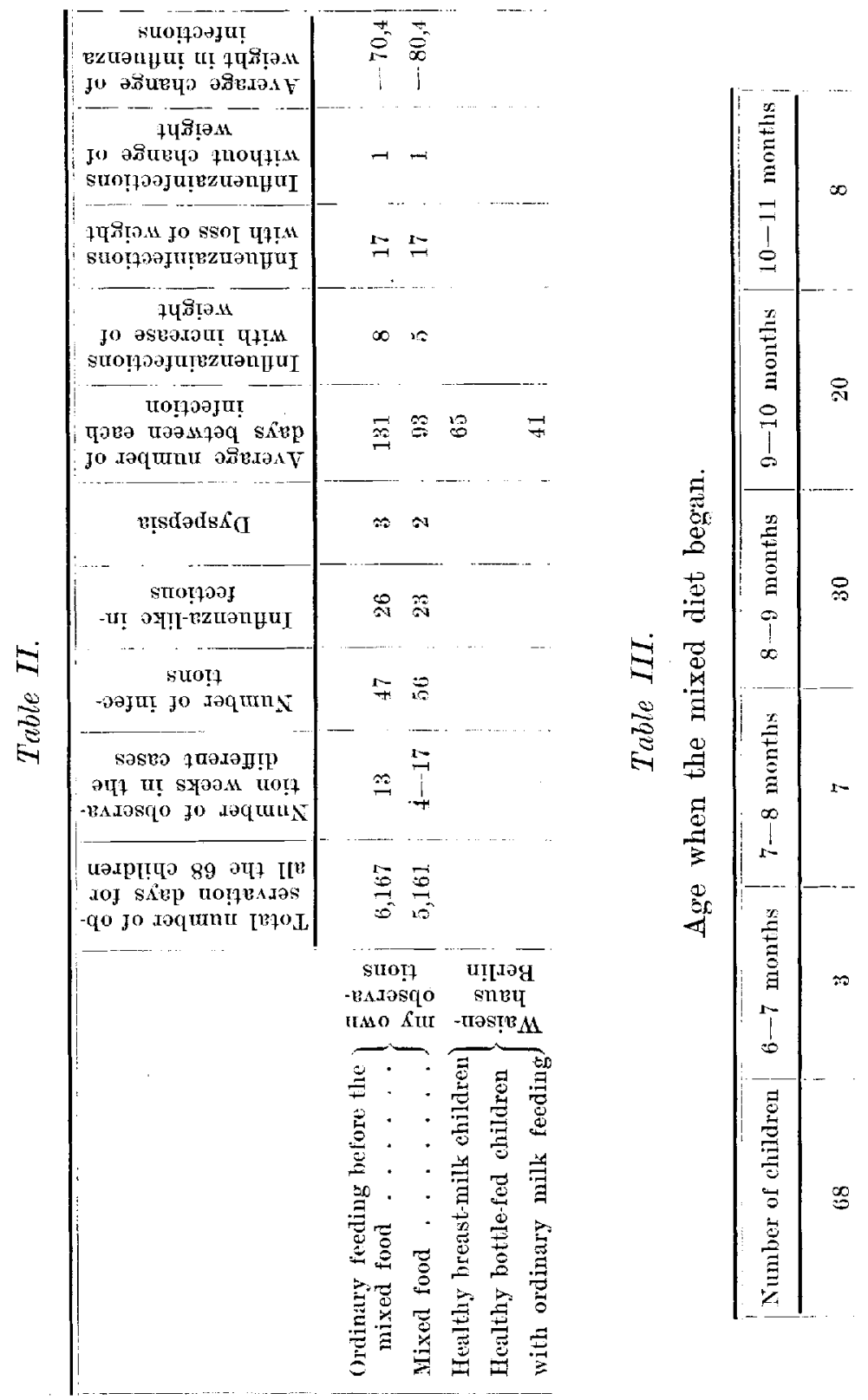


state of health is at its best. Still, in the choice of the above mentioned 68 cases $I$ have not included all the infants, who have been allowed to begin with a mixed diet during the periods in question, but only those, who had been under observation, first of all while getting ordinary milkmixture 15 weeks at least, before they began with mixed diet, and then 4 weeks at least while they were being given mixed diet; thus, the number of weeks of observation, specially examined with regard to the present question, before beginning with the mixed diet, was in all the 68 cases, which I have now closely followed and the weight curves of which I publish here, 13 ; and the number of observation weeks with mixed food 4 to 17 , as is shown by Table II. The children often had to be discharged earlier than might have been wished, and that is the reason why the time of observation for the periods of mixed diet also could not always be as much as 13 weeks.

Table IIT shows, that among the 68 children in question, 3 began with mixed diet at the age of 6 to 7 months, 7 at the age of 7 to 8 months, 30 at the age of 8 to 9 moths, 20 at the age of 9 to 10 months, and 8 at the age of 10 to 11 months. The results of the method of feeding is shown by the 68 curves which I am about to demonstrate. These curves, however, are only curves showing the increase every week, counting backward from the day, when mixed diet was prescribed, and forward from that same day on. The original curves indicating the daily changes in weight are of course more valuable, but for practical reasons $I$ have found it somewhat difficult to communicate them here. ${ }^{1}$

The 68 cases in question may be divided into four groups.

The first group contains 10 cases. In these 10 cases the mixed diet has had an extraordinarily favourable influence on the children's increase in weight and general condition. During the earlier period of observation, lasting at least 13 weeks, the children had either not increased in weight at

${ }^{1}$ For reasons of space and cost, only a few cnres are given in print. All the 68 curves were demonstrated at the lecture. 
all or else increased very slightly. From the day of beginning with the mixed diet, a very considerable increase in weight sets in, and also an improvement of their general condition. In 6 of these 10 cases the earlier development had been unfavourable in spite of their being fed partly with breast-milk and partly by bottle. In these cases the favourable development thus began, when the allaitement mixte was

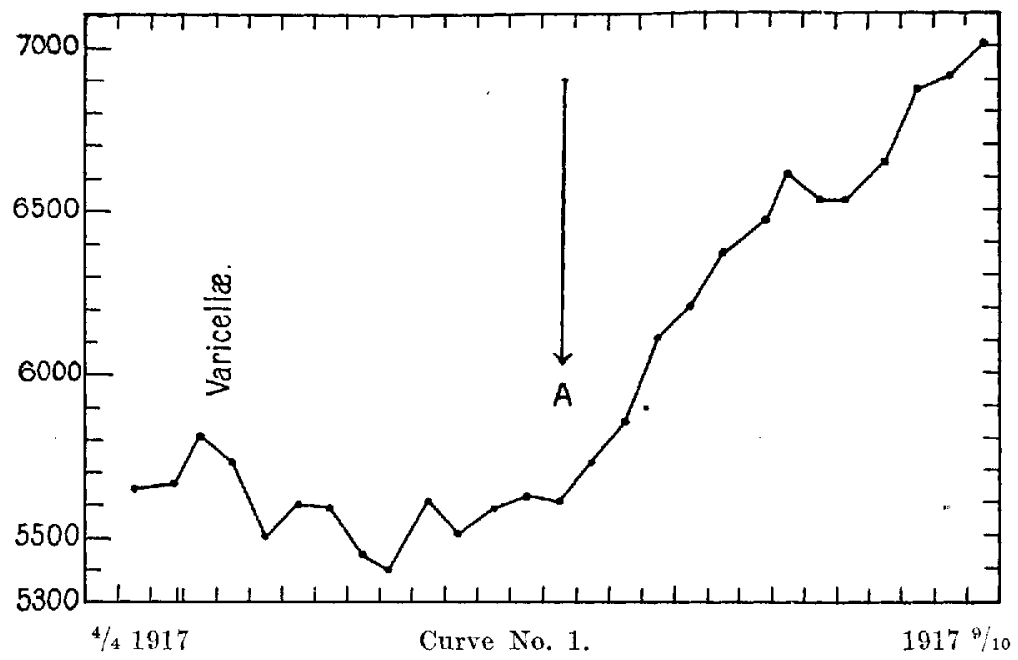

B. R. Born 1/10 1916. Admitted into the Asylum ${ }^{4} / 10$ 1916. Breast-milk till 21 days old, after that allaitement mixte till the age of 9 months 3 days, then mixed diet. Discharged recovered ${ }^{11} / 12$ 1917. Letter $A$ on the curve indicates the day, when the allaitement mixte was changed to mixed diet.

abandoned and the child was given mixed diet instead, without any supply of breast-milk. 4 of the 10 cases had been fed by bottle all the time, or in any case had not got any breastmilk during the mentioned observationperiod of 13 weeks. Curve No. 1 may serve as an instance of those cases, where the mixed diet was given immediately after the allaitement mixte to a child, who had shown a standstill of weight and slow development during this alluitement mixte. 5 more cases show the same favourable effect of a diet of mixed food, which begins immediately after an allaitement mixte, that has

17 - 21219. Acta poediatrica. Vol. I. 
not given a good result. The curve No. 2 shows an instance - of the favourable effect of mixed food on a child, who during the earlier observation period of 13 weeks had been fed only by bottle.

The second group contains 27 cases, in which the result of the mixed feeding must be considered very good. In this group I have included such cases as have shown during all

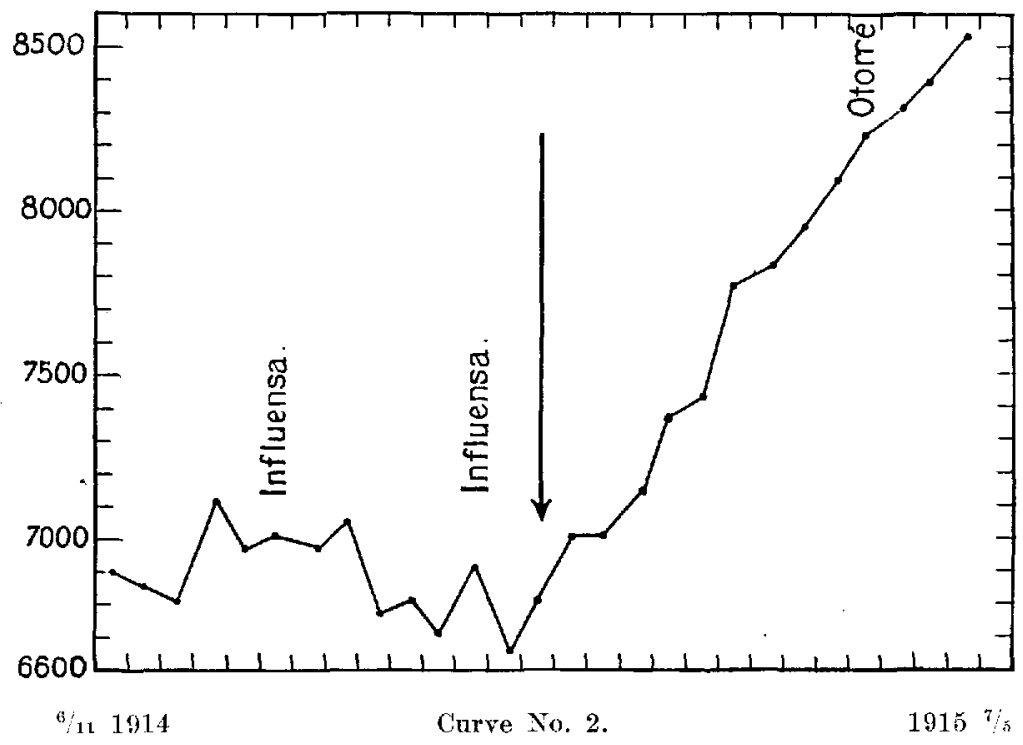

K. A. Born $16 / \theta$ 1914. Admitted into the Asylum $31 / 101914$. Ordinary bottle feeding till 7 months 20 days old, after that mixed diel. Discharged ${ }^{13} / 9$ 1915, died (at the age of 15 months) of pericardit. supp. after pleuropneumia. The arrow indicates the day when the mixed diet was prescribed.

the period of observation, since the mixed feeding began, either an uninterrupted normal increase of weight week by week, or during the whole period of observation a standstill in weight during one week at most, or a decrease in weight of 200 grammes at most, or have shown a standstill or decrease during 2 weeks at most with a total decrease during both those weeks of 200 grammes at most. Evidently these cases belonging to the second group might be said to have 
shown during the treatment with mixed diet fully as good and regular increases of weight, as they showed during the time of observation before beginning the mixed diet. That this result must be considered very favourable, already ap-

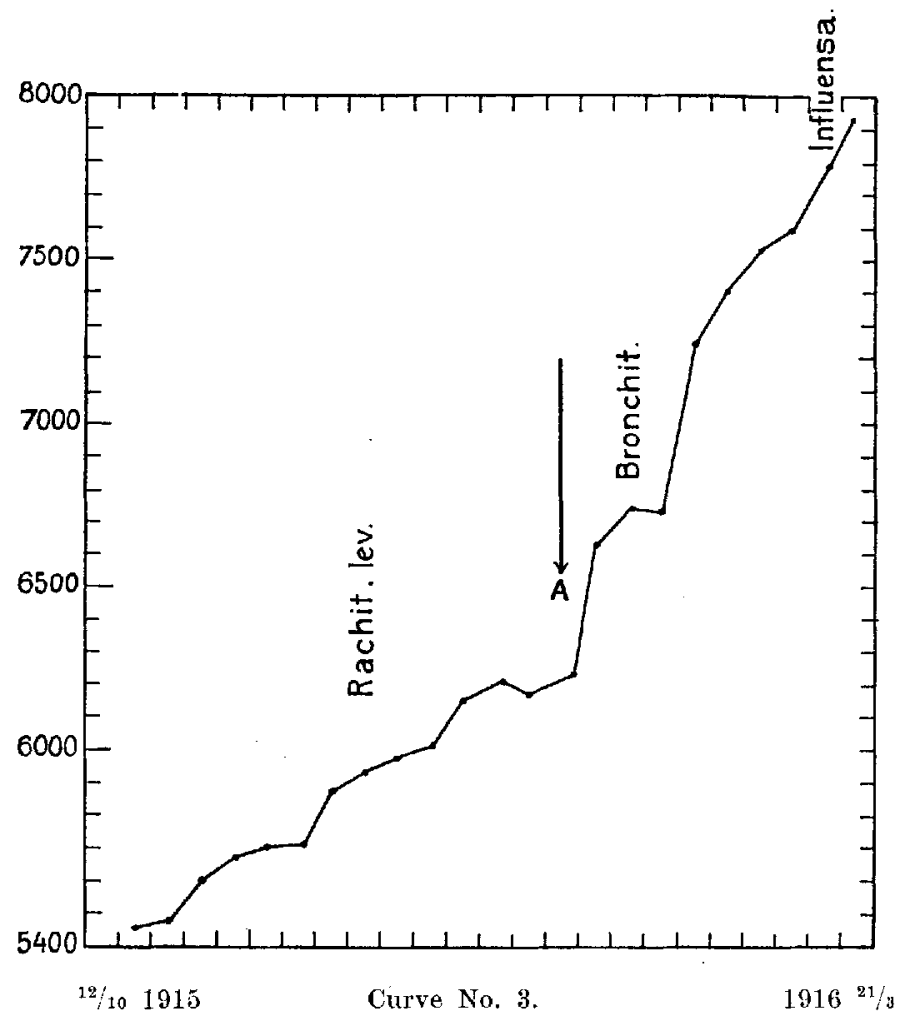

(i. R. Born 11/7 1915. Admitted into the Asylum $13 / 7$ 1915. Allaitement mixte till 6 months old, then mixed diet. Discharged recovered $23 / 31916$. Letter A indicates the day when the allaitement mixte ceased and mixed diet was prescribed.

pears from the fact, that with no less than 18 of these 27 infants the mixed food was begun immediately after an allaitement mixte, which had been continued for a longer or shorter time before administering the mixed diet. Allaitement mixte, as we know, is a method of feeding, that leads to

- 21219. Acta padiatrica. Vol. I. 
particularly good results especially with children in the 2nd and 3rd quarter of their first ycar, and if now the mixed

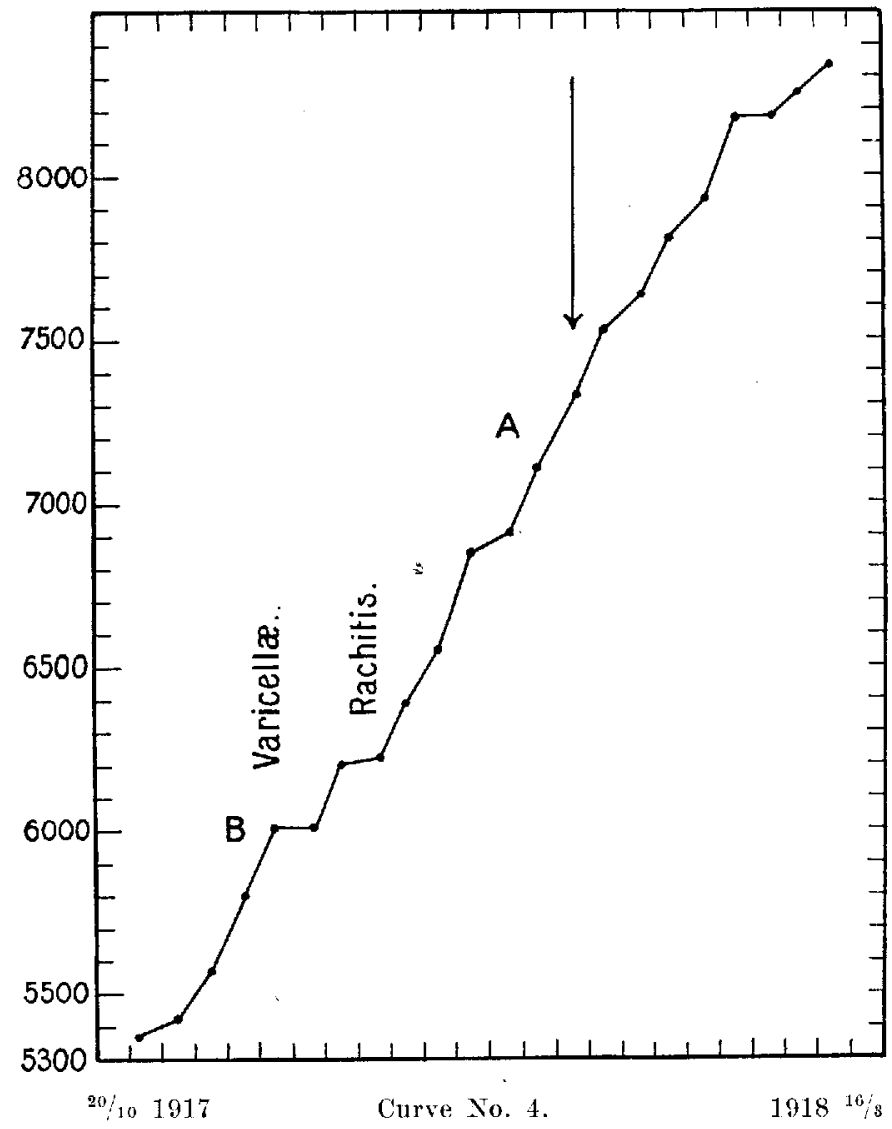

S. K. K. B. Born $17 / 51617$. Admitted into the Asylum ${ }^{22 / 6} 1917$. Breastmilk till 5 months 21 days old, then allaitement mixte till 7 months 18 days old, after that bottle feeding till 8 months 2 days old, and then mixed diet. Discharged recovered $18 / 3$ 1918. Letter $B$ indicates the day when the feeding with breast-milk only ceased; letter A the day, when the allaitement mixte ccased; the arrow indicates the day when the bottle feeding was exchanged for mixed diet.

diet has shown results quite as good, it must be said, that the results of the latter method of feeding have been excellent. The curve No. 3 may serve as an instance of one of 
these 18 cases. In 7 of the 27 cases belonging to the second group the mixed food was preceded by a period of ordinary

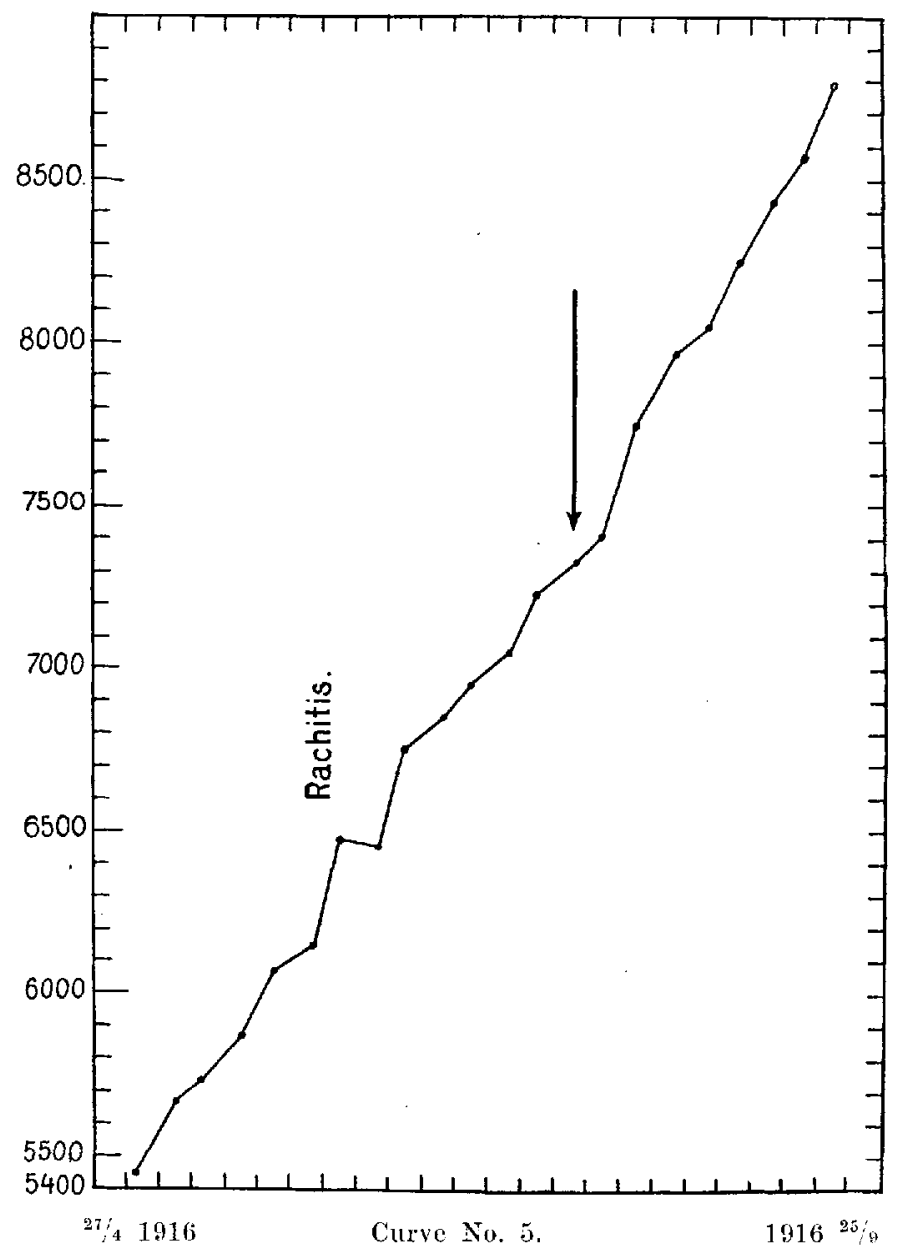

H. G. E. A. Born ${ }^{11 / 11} 1915$. Admitted to the Asylum ${ }^{24} / 2$ 1916. Bottle feeding till 8 months 14 days old, after that mixed diet. Discharged recovered $25 / 9$ 1916. The arrow indicates the day when the ordinary bottle feeding ceased and mixed diet was prescribed.

artificial feeding, the length of which varied in the 7 cases between 2 and 15 weeks. Before this period of artificial feeding these 7 children had had allaitement mixte, and before 
that only breast-milk. For an example of this, see curve No. 4. Among the infants belonging to the second group, 2 had never had any breast-milk. For an example, see curve No. $\check{5}$.

In the third group I have placed 12 cases, where during the whole time of observation with mixed diet the curve shows a loss of weight above 200 grammes, whether this loss

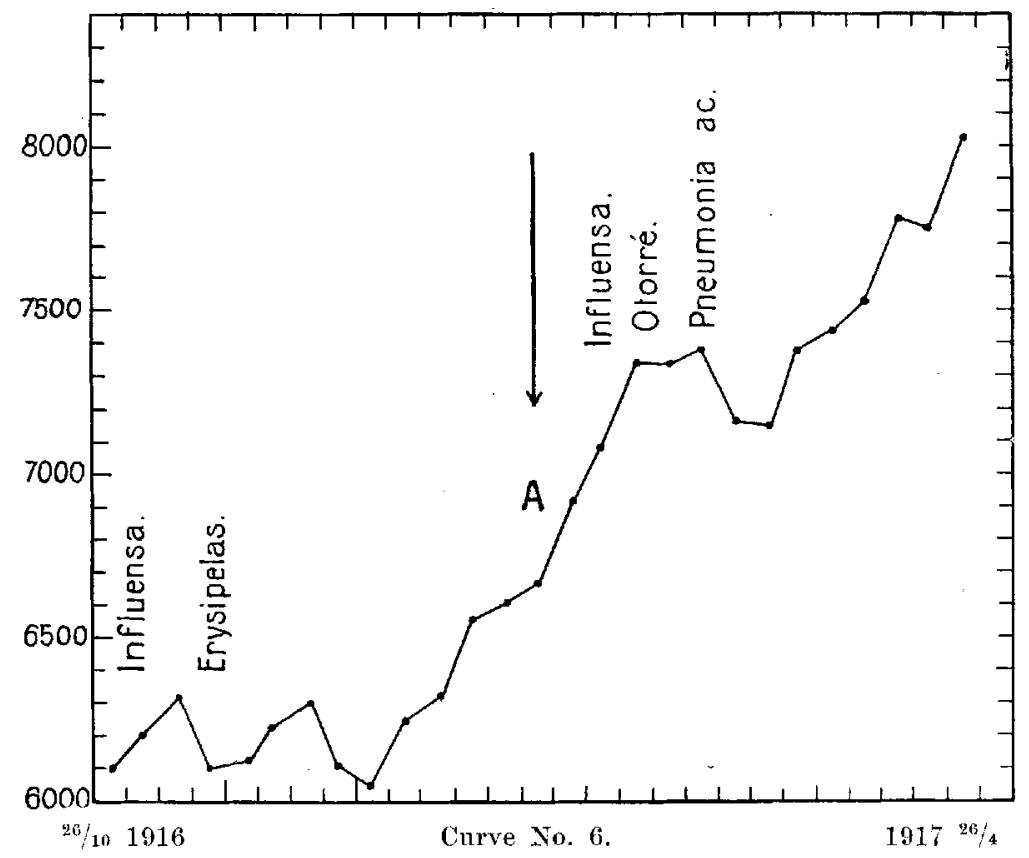

K. O. Born 6/5 1916. Admitted into the Asylum ${ }^{24 / 5}$ 1916. Allaitement mixte till 8 months 9 days ald. After that mixed diet. Discharged recovered $25 / 4$ 1918. Letter A shows the day when the allait. mixte ceased and mixed dict was prescribed.

is localized to one week or extends over 2 or 3 weeks. Still I have only placed the cases in this group, if they plainly show, that at all events the increase in weight during the administration of a mixed diet is not lower than it was before beginning this diet. The curve No. 6 may serve as an example of the cases in the third group. In 8 of these 12 cases the mixed food was administered immediately following 
on the allaitement mixte. In 4 cases a period of 1 to 20 weeks elapsed from the time when the children had allaitement mixte till the mixed food diet was begun.

The fourth group contains 19 cases. To this group I have referred children, who during one whole month of the time of observation with mixed diet have not increased at least 200 grammes, and this quite regardless of the cause of the unfavourable result. In 3 of these 19 cases no such cause could be proved. In all the rest of the cases the bad result was evidently due to infectious diseases (influenza, pneumonia, diphtheria, lymphadenitis, abscesses). In 2 cases of acute pneumonia death ensued. The definite result in these cases at least would not have been better, if another method of artificial feeding had been chosen.

From what has been said it may be gathered, that the result of the mixed diet at the age here indicated has been favourable in the main. In a number of cases this method of feeding has clearly been of the greatest value. This is the case with Group No. 1, where undoubtedly the impression is conveyed, that the change in the diet has had a specially good result.

To avoid breaking off the previous order without cogent reasons the number of meals a day with the mixed diet has been 5 , or the same number as before beginning this diet. On the other hand, the children have been allowed to eat as much as they liked at the meals of mixed diet, and have not, as during the previous bottle feeding, been given measured rations. Otherwise the treatment of the children, who were given the mixed diet, has in no wise differed from the treatment and care of the other children. Therefore, there has in my opinion been scarcely any change in the children's psychical diet, if I may use that expression, but it is essentially the administration of the mixed diet as such, that has to be taken into consideration. In saying this, I have no intention of denying the possibilities of psychical impressions being of some importance also in the treatment of children in elinics. 
I will not conceal the fact, that the results of the treatment with mixed diet in certain respects are not so good as might have been wished. I mean with regard to the regularity of the daily increase in weight. In this respect the mixed diet does not, in the method I have employed up till now, show the desired regularity. 'Too large increases in weight often enough sncceed arrests or decreases. In a number of cases this has evidently been due to the fact, that the children have objected to certain kinds of food offered to them, whereas they have eaten very large quantities (for instance up to $400-500$ grammes of porridge or fruit-juice) of other kinds, that have been more palatable to them. I believe it possible to succeed in aroiding these fluctuations through certain modifications, especially by supplying more fat, and thus arriving at more regular increases in weight. (This will be described in a subsequent paper).

The result of a method of feeding is judged, as we know, not only by weight curves, but also by a number of other circumstances. Many of these circumstances, however, for instance the state of the child's turgor and tonus, temper, sleep etc., are difficult to describe objectively, in this respect we are thrown upon our subjective interpretation, against which others have a right to take up a sceptical attitude. One of the most important signs of a child's proper development is its resistance to infection, and in the possibility of proving a smaller or larger power of resistance we have a fairly objective standard for judging the value of a certain method of feeding. I have therefore observed more closely the occurrence of infections during the periods, wher the children have been given ordinary milk mixture and compared the number of infections during these periods to the number of infections during the periods of mixed diet. The result of this comparison is shown by Table II. We see from this table, that the number of special observation days with the 68 children in question during ordinary feeding was 6,167 , and the number of observation days with mixed food 5,161 . During the days of observation with ordinary feeding these 
68 children had in all 47 infections, among them 26 influenzalike infections. During the period of mixed food diet there were in all 56 infections, of which 23 influenza-like. The average number of days between each infection was with the ordinary feeding 131, the average number of days between each infection during the period of mixed food was 93 .

The greatest interest with regard to these infections is attached to those of an influenza-like kind. This is because the more specific ailments appear more capricionsly and hardly show the same regularity as the influenza-like infections referred to. (By influenza I do not here mean the specific pandemic influenza, but the ordinary catarrhal infections of the upper air passages, accompanied by fever; what the Germans call "Grippe"; epidemic influenza only appeared in the Orphan Asylum in September 1918, and thus at a time outside the period of observation for the 68 cases here discussed). Among the mentioned 26 influenza-like infections with ordinary feeding 8 showed increase in weight, 17 decrease, and 1 no change in the weight. The corresponding figures during the mixed diet were: 5 with increase, 17 with decrease, and 1 without any change. The average loss of weight in the infuenza-like infections during ordinary feeding was 70,4 grammes. The average loss of weight in these infections during mixed diet was 80,4 grammes. These results also must be said to be farourable, especially if it is taken into consideration that the feeding before the mixed diet was begun was in the majority of cases allaitement mixte.

As to the mortality among the total number of children fed on mixed diet, this was $3,14 \%$ (12 of 382 ). The mortality among the total number of infants tended in the Orphan Asylum during the years $1914-1918$ was $4,90 \%(107$ of 2,186$)$. The mortality among all those who had got mixed diet was consequently low in itself; still the figures given do not allow of any real comparison between the mortality among infants fed by bottle and that among those that got mixed diet, as the children had not immediately on their admission into the Orphan Asylum been so divided, that every alternate child 
Table IT.

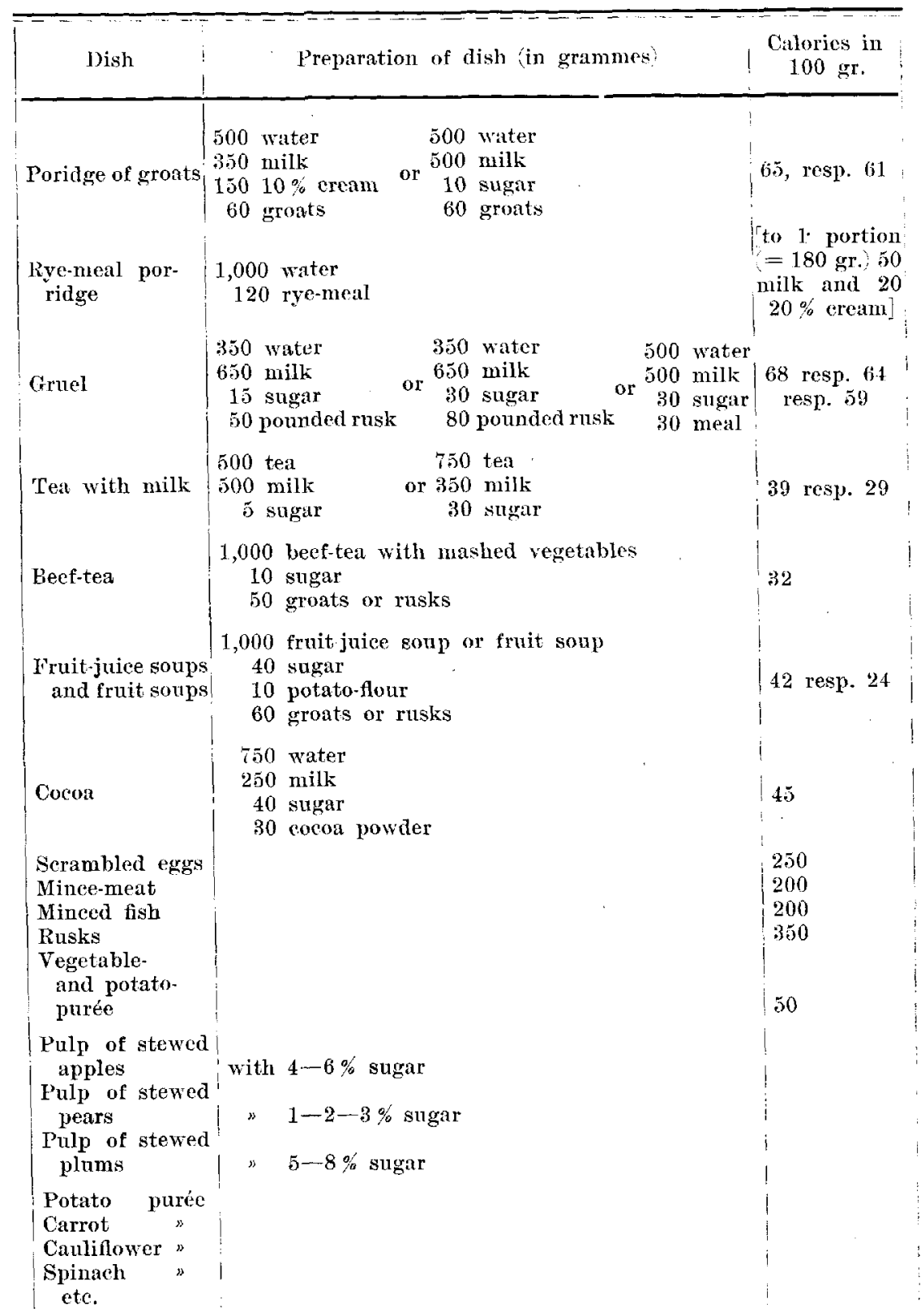


was designated for mixed diet and for feeding according to the ordinary rules.

As to the diet prescribed, the nature and composition of the dishes appear from Table IV without much further comment. We see that the diet consisted of porridge, gruel, tea with milk, beef-tea, fruit-juice soups, fruit soups, cocoa, scrambled eggs, mince-meat, minced fish, rusks, mashed potatoes and various vegetables and different kinds of pulp of stewed fruit. The preparation of some of the dishes is indicated in the table. Where it is not, the dishes have been prepared in the ordinary household way, only with the difference that the mincing of the ingredients (for instance in the preparation of the mince-meat, minced fish, the mashed potatoes and vegretables and the stewed fruit) has been extremely careful. The total quantity of milk that the child got per day was generally fairly small, varying between $300-550$ cubic centimetres. At every meal and of all the dishes the children were allowed to eat as much as they wished. The amount of milk was limited through fixing the quantity contained in the different dishes, of which the children were allowed to eat as much as they wished, and no other milk besides this was given to them.

While making these observations I have not had any intention of laying it down as a rule, that mixed diet ought to be given to children, who have entered their third quarter of a year. Before pronouncing such an opinion numerous further experiments with mixed diet and investigations into the manner in which such diet is best given, are necessary. What my experiments show, however, is that there is evidently no risk in giving mixed food to a child, who has passed into its third quarter, and that such feeding in certain cases may have a very favourable effect on the child's health and may even be quite necessary for a good development. This ought to be kept in mind, if one has to undertake the care of children in the third quarter of their first year, who do not show a good development with the ordinary, hitherto usual, method of feeding. 